\title{
Sven Nykvist
}

\section{El credo del fotógrafo}

\begin{abstract}
Credo es latín, y significa profesión de fe. No soy latinista ni "creyente» en el sentido en que lo eran mis padres, pero hay muchas cosas en las que he aprendido a creer, tanto a través de mi trabajo como de mi experiencia vital. De esto es de lo que quiero hablar un poco aquí, y como credo - profesión- parece sonar menos pretencioso que profesión de fe, pues le pongo de título el credo de un profesional. Los libros de confesiones no van conmigo. Pero sin duda soy un profesional. Cuando escribo esto llevo cincuenta y cinco años trabajando activamente, y he firmado, como ya queda dicho, ciento veintiséis largometrajes.
\end{abstract}

\section{CULTO AL TRABAJO}

Como profesional soy humilde y perfeccionista. La humildad la aprendí de Albert Schweitzer; tener paciencia y salirse con la suya sin levantar la voz. Y fue él también quien me proporcionó mi primer lema: «culto al trabajo», paráfrasis del suyo, "culto a la vida.

Es un buen lema. En la palabra culto no leo yo sumisión sino respeto, gratitud y orgullo. Gratitud por el simple hecho de tener un trabajo y además por ser tan privilegiado de tener el trabajo que uno ama. Creo que no ha pasado ni un solo día en mi vida sin que haya estado contento con mi profesión.

El perfeccionismo lo aprendí de Ingmar Bergman; la importancia de la minuciosidad, de no confiar nunca en la rutina, de no decir nunca que algo es imposible, y de no rendirse jamás.
Más de una vez dije: «No se puede». «Claro que se puede" - contestaba Bergman.

Por lo general él tenía razón, y yo aprendía algo nuevo. Uno no se puede llamar profesional hasta que aprende el oficio de verdad, hasta que se dominan todos sus aspectos. No hace falta que sean siempre cosas difíciles o complicadas. Recuerdo el día en que aprendí a cargar y cambiar el chasis de una cámara, cuando aprendí a distinguir los objetivos. Me sentí orgulloso de haberlo hecho y eso era ya orgullo profesional. Creo que es importante sentirse satisfecho por lo que se ha aprendido a dominar y a realizar. Ya se sea cocinero o enfermera, operador o tornero.

Si se tienen ambiciones y talento, ganas y voluntad de seguir adelante en el oficio, hay que aprender otras 
muchas cosas, y estar dispuesto a asumir mayores responsabilidades. Obviamente existe una cierta jerarquía, pero yo he tenido ocasión, casi a diario, de sentir en el rodaje una gran gratitud hacia todos aquellos que me ayudaban con orgullo profesional. No todos los fotógrafos pueden ser directores de fotografía, tampoco todos quieren serlo. En cambio todos los eléctricos puede ser jefe de eléctricos. Por no hablar de ese importantísimo sector del equipo cinematográfico que corresponde a los ayudantes. Lo que llevan y cargan, preparan y arreglan, los que siempre están en su sitio dispuestos a echar una mano cuando más lo necesitamos. A menudo sin necesidad siquiera de pedírselo. Saben lo que hay que hacer.

Desde hace muchos años Ingmar Bergman concede un premio Bergman, creado por el Instituto de Cine sueco, una suma de dinero y un diploma. Uno de los primeros años se lo otorgó a mi ayudante de cámara, Lasse Karlsson, a quien calificó de «Mozart de los foquistas». Lasse es un ayudante formidable, ya no sé ni cuántas películas hemos hecho juntos. Su mayor ambición radica en que el foco esté siempre bien, independientemente de lo complicado que sean los travellings o los movimientos de cámara. Es un hombre muy serio y no suele reírse, pero cuando vemos el copión del día y comprueba que las tomas están perfectamente enfocadas, sonríe. Eso es orgullo profesional.

Una experiencia parecida he vivido con Jeff Cronenwerth, que en las últimas ocho películas rodadas en Estados Unidos ha sido mi fiel segundo, es decir el que permanece sentado detrás de la cámara, ya que al director de fotografía se lo impiden los reglamentos de los sindicatos americanos.

A veces he echado de menos ese aspecto de mi trabajo, aunque por otra parte eso significó que puedo concentrarme en lo que más me interesa -la iluminación-, al poder olvidarme de cualquier aspecto «manual». Todavía recuerdo lo avergonzado que me sentí en cierta ocasión cuando mandé a mi segundo en una barca para tomar simultáneamente la misma escena con dos cámaras, y me di cuenta de que no sabía cargar la mía.

Reconozco que no soy un técnico y que me siento razonablemente desinteresado por la maquinaria. Incluso me gustan muy poco los momentos puramente técnicos de mi trabajo. En este campo, la mayoría de los operadores pueden ganarme fácilmente, y hay muchos que adoran los movimientos de cámara, las escenas complicadas.

Lo importante para mí es la búsqueda creativa, y en eso me guío más por la experiencia y la sensibilidad que por fotómetros y cintas métricas. Para mí la técnica es simplemente una base sobre la que apoyarse, un medio, nunca un fin. Sobre todo, no puede ser un fin en sí mismo. La técnica ha de ser la servidora de la creatividad, no su dueña y señor. De lo que se trata es de dirigir la técnica de manera que el resultado final sea artístico. Lo más difícil, y lo más interesante también. Cuando era joven, en los tiempos del blanco y negro, el operador que llevaba más filtros de luz era considerado rey. Yo no participaba de ese amor a los filtros entonces, y tampoco ahora. Cumplen una función pero se deben utilizar con prudencia. Hoy pienso que, en principio, mi trabajo debe ser invisible. El guión es el punto de partida de una película. El director es quien lo interpreta y dirige la puesta en escena. Los actores le dan vida. La misión del operador es la de reflejar las intenciones del guión, y la interpretación que el director hace de ellas.

Por eso, en este orden de cosas quiero subrayar con 
entusiasmo la importancia de la colaboración: para mí la colaboración es fundamental en un rodaje, con el director, con los actores para que no les moleste el trabajo del iluminador ni les den los focos en los ojos, con los maquilladores, con los escenógrafos y sus intenciones en lo que respecta a la elección de color y disposición de materiales, en dos palabras con todos los engranajes de esa maquinaria de aportaciones laborales que componen una película.

No parece necesario mencionar la importancia que tiene la compenetración con el equipo de cámara y con los eléctricos. Para un operador es la base. Por eso resulta extraordinariamente valioso poder trabajar siempre con el mismo equipo. Esto lo aprendí, sobre todo, en los rodajes con Ingmar Bergman, a quien también le gusta utilizar a los mismos actores. Y tanto en Alemania como en Estados Unidos he logrado muchas veces contar con los mismos asistentes película tras película. Con eso ganamos todos, incluido el productor. Hay eléctricos a los que no necesito decirles una palabra. Un movimiento de cabeza y comprenden exactamente lo que quiero decir. Nos comunicamos con el «lenguaje del cine», aunque no hablemos el mismo idioma.

\section{CULTO A LA LUZ}

No cabe duda de que fue Ingmar Bergman el que me enseñó a sentir veneración (respecto, gratitud) por la luz, la luz real, verdadera y viva. Ya he contado cómo ocurrió. Fue trabajando en aquellas película en blanco y negro Detrás de un vidrio oscuro, Luz de invierno, Silencio y Persona, y luego en color, Pasión y Gritos y susurros. Veo esas seis películas como puntos de referencia en mi camino hacia el descubri- miento de la luz. Duró doce años, pero no consideré que con esto hubiera acabado mi aprendizaje. La luz ofrece constantemente nuevas sorpresas, aunque ahora contara con buena base para apoyarme.

Antes, en los años cuarenta y cincuenta - para la mayoría de los operadores incluso más tarde-, lo importante era disponer del máximo de luz posible, una luz general plana en la que se insertaban efectos en forma de hermosas formaciones de nubes, sombras dramáticas, puntos de luz, o contraluces por detrás del cabello de la heroína. Cuantos más «efectos», mejor fotografía. Pero las imágenes de una película no deben existir por sí mismas. No hay nada más fácil que conseguir imágenes hermosas, aparatosamente iluminadas y adornadas con efectos, y no hay nada más difícil que tomar imágenes que se subordinen a la acción y «cuenten» la historia.

Cuando llegó el color era preciso poner el máximo de color posible y con preferencia los tonos más fuertes. «Si he pagado por el color, pues tiene que haber color», me gritó un productor cuando atenué en el laboratorio los tonos demasiados chillones.

Claro que siempre hubo iluminadores excepcionalmente dotados, sobre todo en tiempos del cine mudo. Posiblemente eran tan buenos precisamente porque no disponían de tantos recursos técnicos como hoy. Debían arreglárselas con lo que tenían a mano. iObserven el trabajo de Julius Jaenzon y las películas que fotografió para Sjöstrom y Stiller! iVaya si sabía manejarse con la luz!

Sin embargo yo pude ver sus películas mucho después. Mi primer ídolo como director de fotografía fue Greg Toland, quien en los años cuarenta hizo películas de John Ford, como Viñas de ira, El ciudadano de Orson Welles y La loba y Lo mejor de nuestra vi- 
da de William Wyler. Guardo un viejo álbum de recortes de mis inicios y en la primera página aparece una fotografía de Greg Toland. En su caso admiraba la sensibilidad y atmósfera de las imágenes pero también la técnica de la profundidad de campo, con todo en foco desde lo que se veía delante hasta lo que estaba en el fondo. Esto permitía a los actores adquirir relevancia, independientemente de la distancia a la que se encontraban de la cámara.

Hoy la mayoría de los operadores utiliza una profundidad de campo mínima, a menudo solo porque les da mayor control sobre el punto donde se dirige la vista del espectador, aunque también tenga que ver con esto la futura exhibición de la película por televisión, en lo que no había que pensar antes. Esto contribuye a que muchas de las películas actuales sean tan aburridas de ver. La narración en imágenes queda plana. No han sido concebidas para ser contempladas en una gran pantalla de cine sino para «informar» en la de un televisor.

La televisión no hace justicia a una buena iluminación, aunque como el primer plano de una persona es lo que mejor se da en ese medio, yo encuentre cierto consuelo, dado mi interés por los rostros.

Fue también Ingmar quien despertó en mí el interés por los rostros, y sus constantes cambios en los rasgos y en las miradas. La verdad suele anidar en los ojos del actor. Si muestran los ojos, desnudan el alma. Un rostro expresivo puede por sí mismo contar una historia. Una mirada puede decir más que mil palabras, parafraseando esa frase por la que obviamente tengo la mayor simpatía, incluso en su forma original. Si el actor es bueno y la química funciona, cabe arrancar su belleza interior, eso es pura magia.

Ingmar se atreve a mantener un primer plano mucho tiempo, incluso varios minutos. Basta con pensar en la Ingrid Thulin de Luz de invierno, Liv Ullman de Pasión, en Bibi Andersson y Liv en Persona, en la Harriet Andersson de Gritos y susurros. Más de una vez sus actuaciones me conmovieron de tal forma que llegaron a saltárseme las lágrimas y casi empaño el visor, aun cuando hubiera presenciado los ensayos y me supiera sus caras al derecho y al revés.

Aprender a conocer un rostro para poder iluminarlo adecuadamente y darle las mejores oportunidades de presentarlo por su lado mejor, es para mí fundamental. Quizá no parezca tan difícil, pero en realidad forma parte de las cosas más arduas que existen, porque se trata de matices muy, pero muy pequeños. Ya he contado que me gusta mantener a los actores en su sitio mientras ilumino, cosa que en el extranjero apenas pueden entender, pero lo hago precisamente por eso, porque quiero aprenderme las caras.

Afirmar que cada cara es única parece una perogrullada, pero no a todos preocupa la diferencia de sensibilidad que pueden ofrecer para la luz. Por eso resulta tan importante que el iluminador colabore con el maquillador, y haga con él todas las pruebas necesarias. También es importante que se le explique al actor lo que uno hace, y por qué. No deben sentirse nunca manipulados, o utilizados sin consideración.

De ahí que trabaje siempre muy cerca de ellos. Mi tarea consiste en convertir la cámara en su mejor amigo. Trato de ser una especie de intermediario sensible entre el actor y el objetivo. Es esencial que se sientan seguros, y que la cámara y la iluminación no los moleste.

El actor es, y seguirá siéndolo, el instrumento más importante en una película. La misión del operador reside en captar las reacciones de ese instrumento, 


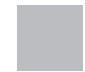

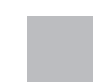

Sven Nykvist con Bergman
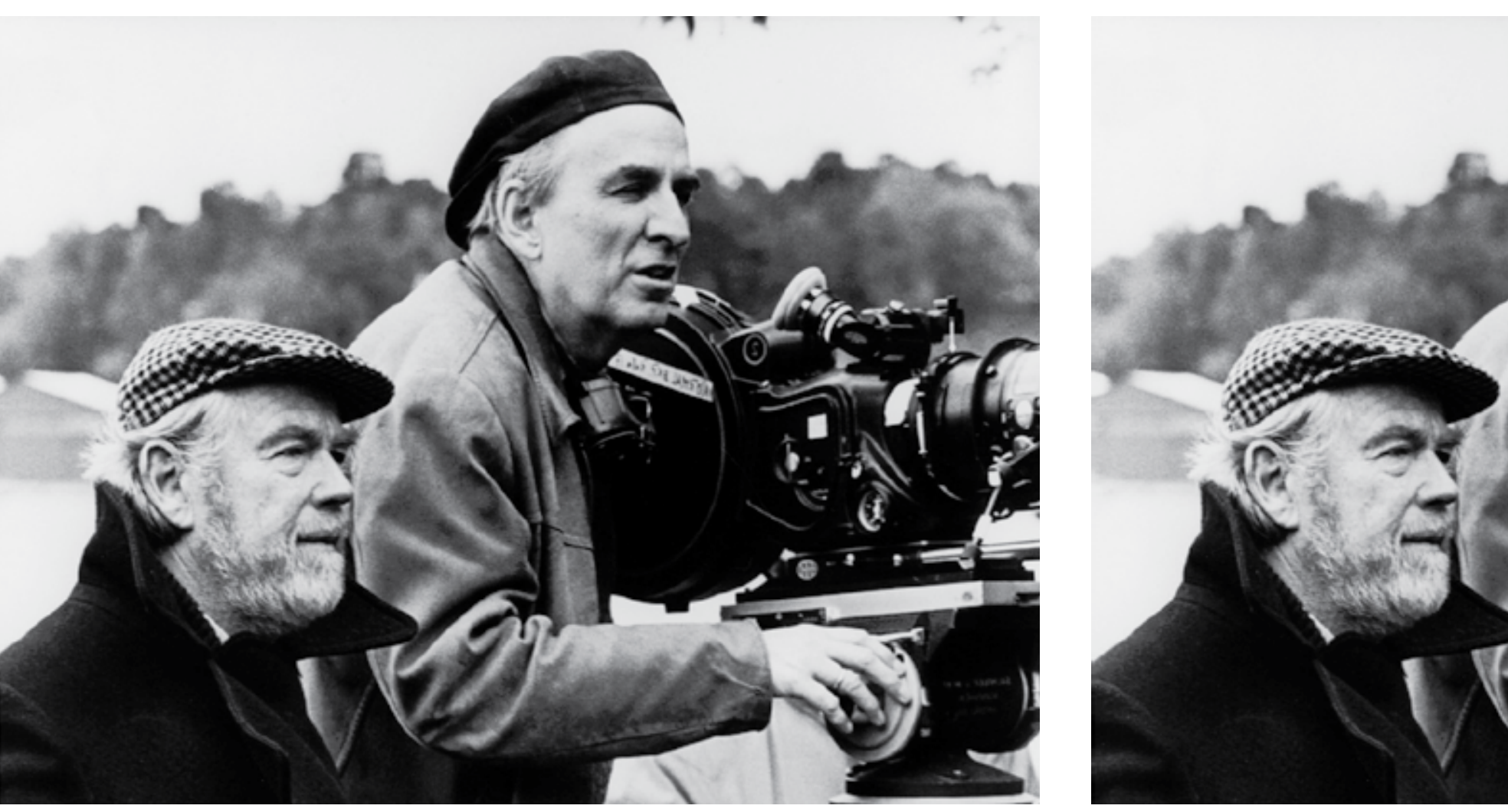
en centrar la atención del espectador en el carácter y la expresividad de un rostro. Eso se consigue disponiendo diferentes luces para cada uno de ellos. Un rostro no tiene por qué estar bellamente iluminado. Las sombras forman parte de nuestra vida.

Nada de esto es nuevo. Los grandes retratistas siempre lo han sabido. Miren a Rembrandt, y sus famosos claroscuros, una luminosa penumbra que proporciona atmósfera a un rostro iluminándole ciertas partes, y dejando otras en sombra. Miren a Renoir. Con qué ternura esculpe los reflejos de la luz en los cuerpos de las mujeres. Los pintores me han inspirado mucho $y$ hay quien ha dicho que yo «pinto con luz".

Creo recordar que esta expresión me la aplicaron por primera vez en relación con una película alemana hecha en 1969, la de Maximilian Schell Erste Liebe, adaptación de una novela de Turgeniev. Desde entonces la frase se ha repetido bastantes veces, lo cual, obviamente, me alegra y me enorgullece.

Sin embargo, no me he dejado inspirar solamente por los retratos. También de los paisajistas se puede aprender mucho. Ya he hablado de cómo estudiaba a los impresionistas cuando rodaba en París. Nuestro Anders Zorn no pintaba solo chicas de la región de Dalecarlia. Era extraordinariamente hábil en captar los reflejos del agua. Observen su Danza de San Juan; es un cuadro que tiene una luz casi mágica. También los pintores daneses de Skagen me enseñaron muchísimo sobre la tan especial luz nórdica, cómo el sol traspasa filtros de nubes y crea un paisaje en colores pastel.

Siento cierta proximidad especial a Anna Ancher. Su manera de aprovechar en los interiores la luz que entra de fuera. Tiene un cuadro, La criada trabajando, en el que una mujer joven está de espaldas al obser- vador junto a una mesa de trabajo cerca de la ventana. Ha colgado una tela de color amarillo claro en esa ventana, y todo el espacio que ocupa recibe el ligero tono amarillo de la luz que penetra por la ventana. No hubiera podido iluminarlo mejor en un estudio cinematográfico.

William Turner es otro de mis favoritos. Se puede ver realmente cómo ha tenido que estudiar la luz en todos sus matices. Constituía una obsesión para él, según dicen. En cierta ocasión se hizo atar al mástil de un barco para estudiar a fondo una tempestad antes de pintarla. Su profesor le dio una vez un consejo que yo podía haber aceptado al pie de la letra: «Cuanto menos se ven las huellas de los medios con los que se ha realizado un trabajo, más se parecerá el resultado a los procesos de la naturaleza».

El fotógrafo Ansel Adams se encuentra entre mis ídolos. He peregrinado hasta Carmel, en la costa del oeste norteamericano, solo para poder conocerlo. En lo que concierne a la luz, es increíble, claro que él podía estar esperando la luz exacta una eternidad.

Eso, para un operador en plena filmación, es imposible. Aunque recuerdo una vez... Ingmar buscaba a toda costa unos paisajes muy especiales, a la salida del sol, en una zona de la montaña, para el comienzo de EI silencio. Yo no tenía tiempo, porque debía estar planeando el rodaje con él, así que enviamos a un colega muy capaz, Lasse Björne. Creo recordar que anduvo por aquellas latitudes varias semanas antes de conseguir las imágenes que pretendía Ingmar.

El estudio de la luz ha enriquecido mi vida enormemente. Adoro, por ejemplo, los amaneceres y los crepúsculos suecos, la ruptura que se produce cuando la luz del día llega o desaparece. Sobre todo esto último, la mágica hora azul, «the magic hour», la hora 
del lobo, cuando la luz artificial, lámparas y farolas, va imponiéndose lentamente. Hay un instante en que están en equilibrio. Nunca me canso de analizarlo.

Pero también estudio la luz dondequiera que vaya. Hasta cuando entro en un restaurante. Lo primero que pienso es cómo han iluminado el local, cómo caen las sombras sobre los rostros. Mi recuerdo de una persona suele ser la atmósfera de su rostro bajo una luz determinada.

La luz se ha convertido en la pasión que domina mi vida, y le ha dado un nuevo sentido, y no sólo como fotógrafo. Parece hermoso sentirse siempre rodeado de luz. Me da una sensación de atmósfera espiritual. Tienes la luz y no cabe sentirte solo.

Por eso creo importante citar lo que dice Ingmar Bergman de nuestra manera de ver en su libro Linterna mágica:

Ambos estamos totalmente fascinados por la problemática y la magia de la luz. La luz suave, peligrosa, onírica, viva, muerta, clara, brumosa, repentina, oscura, primaveral, cálida, violenta, fría, vertical, lineal, oblicua, sensual, domeñada, limitadora, serena, venenosa, luminosa. iLA LUZ!

\section{LA CLAVE SE LLAMA SENCILLEZ}

Mi afán de sencillez ha ido surgiendo de mi búsqueda de la luz lógica, la real, la verdadera. Esto lo he conseguido reduciendo la luz artificial todo lo que podía para, en cambio, aprovechar la existente. No voy a negar que tal proceso se ha visto simplificado enormemente por la aparición de negativos mucho más sensibles, pero en el fondo no cambian nada. Uno consigue luz natural utilizando un número menor de focos, quizá ninguno. A veces he llegado a arreglár- melas con lámparas de querosene o incluso velas. Quiza esta austeridad luminosa provenga del hecho de que nosotros en Suecia tengamos tan poca luz si comparamos con los países meridionales y, sobre todo, con Estados Unidos, aunque la nuestra ofrece mayores matices y resulta más hermosa. En California la constante luz del sol complica el rodaje en exteriores. En Suecia es mucho más gratificante trabajar al aire libre por la rica variedad de la luz cambiante; sobre todo en otoño y primavera.

Observando esta hermosa luz nuestra aprendí que la sencillez es la clave. Less is more (menos implica más), como afirma un dicho americano, lo que en mi caso significa que un menor número de focos proporcionan luz más auténtica. De manera que otro lema favorito podría ser: poca luz, poco color.

Así es como se construyen los ambientes y las atmósferas, tan necesarios para cualquier narración cinematográfica. Suele decirse que un buen guión cuenta lo que pasa y lo que se dice, no lo que uno siente o piensa. Hay en eso mucho de verdad. Los sentimientos, imprescindibles por otra parte, no se captan con palabras sino a través de imágenes, con rostros y atmósferas. Según mi experiencia, nada puede romper con mayor facilidad un ambiente o estropear una atmósfera, que un exceso de luz.

En el fondo, lo sabemos todos. ¿Quién no ha tenido que frenar a alguien que ha ido a encender una luz eléctrica cegadora cuando, después de una buena cena, seguíamos hablando a la luz de las velas, en la intimidad del anochecer?

Crear ambientes y atmósferas es lo más importante en el trabajo de un director de fotografía. El público no solo deber ver una película, sino recibir también un sentimiento. Por eso es misión del iluminador si- 
tuar al espectador en el ambiente que mejor transmita ese sentimiento.

No me pregunten cómo lo hago, exceptuando que por regla general utilizo poca luz y poco color, como acabo de decir. Me llega como una inspiración cuando estoy allí al lado de la cámara. No puedo decir más. Cada situación es diferente, única. Pensar de antemano cómo se debe hacer resulta imposible, al menos para mí.

Me gusta seguir los ensayos de los actores, sin cámara. Sólo ver lo que pasa, cómo actúan, qué gestos hacen, y sus movimientos. Luego trato de adecuar el juego de la cámara. Hay tantas posibilidades, panorámicas, travellings, grúas... Todas tienen en común que influyen en la iluminación, la determinan, por lo cual se trata de elegir la más adecuada a la situación, y la menos complicada. La «libertad» de los actores debe ser lo prioritario.

Por eso es una gran ventaja practica una iluminación rápida. Los actores no se encuentran a gusto con largas esperas tras haber ensayado la escena, literalmente aguardan en las marcas de salida dispuestos a dar lo mejor de sí mismos. Uno siente sus ojos clavados en la espalda, y debe pensar que una escena bien interpretada es más importante que un ajuste técnico. También en este caso las soluciones más sencillas son preferibles, y no es raro que den mejor resultado. Como se ve, lo de less is more sirve en la mayoría de los casos. Los actores formados en el teatro tienen tendencia a sobreactuar. Less is more! Los largos travellings suelen provocar tedio. Less is more! Los zooms rápidos y evidentes pueden resultar irritantes. Less is more! Demasiada luz deja plana la imagen. Less is more! Demasiada luz deja plana la imagen. Less is more!
¿Me atreveré a decir que eso vale también para los diálogos? En mi opinión, un gran número de películas quedan destrozadas por su insensata cháchara, aunque tal vez dependa todo de que soy fotógrafo. Adoro muchas películas mudas porque cuentan en imágenes de una manera especialmente concentrada. La carreta fantasma, de Victor Sjöstrom, El tesoro de Arne, de Mauritz Stiller, la Juana de Arco de Dreyer. O una película moderna como El árbol de los zuecos, de Ermanno Olmi. Me sentí tan feliz viéndola. Demuestra que todavía se puede narrar sin tanta palabrería.

No creo contar con un estilo especial como director de fotografía - aparte de que en primer lugar trate siempre de cumplir las intenciones del guión y las visiones del director- , pero de tener alguno sería el que corresponde a ese concepto de la simplificación, tanto en lo tocante a composición como a movimiento e iluminación.

Mucho suele depender de las circunstancias, y de con quién se trabaja. No existen fórmulas que se puedan aplica a todo. Cada uno ha de poder trabajar como le parezca. Películas diferentes deben tener imágenes diferentes. Una vez Ingmar Bergman y Fellini llegaron a tener planes bastante avanzados para hacer una película juntos, dos historias de amor. EI guión y todo lo demás estaba listo. Ingmar y yo llegamos a ir a Cinecittà para ver los estudios. Yo dije que en aquel plató tan enorme tendría que disponer por lo menos de cinco arcos brutos, el más grande que existe. El jefe de los eléctricos me miró despectivo: «¿Cinco? Cuando Rotunno iluminó la última película de Fellini utilizó cien».

Ya lo he dicho también: una imagen no existe nunca por sí misma. Está ahí para contar el desarrollo de la 
acción y si aparece demasiado recargada y ofrece demasiado contenido puede ocurrir que el público no capte lo esencial. Por eso me hago siempre dos preguntas antes de preparar una imagen e iluminarla: ¿qué quiere decir el director y qué le interesa ver al público? Después compongo el plano y busco la mayor sencillez posible.

Esto no quiere decir que la imagen no pueda tener audacia. A veces hay que atreverse a ir un paso más allá, a experimentar. La nouvelle vague, la nueva ola francesa de finales de los años cincuenta, significó mucho para el desarrollo del cine gracias a que los directores - y los operadores - se atrevieran a romper las convenciones. Y lo solían hacer simplificando.

Todavía hoy puedo dejar perplejo a mi equipo americano cuando me permito algunos de esos pecados contra lo convenido. Hace un par de años rodaba con Norman Jewison en Italia una ligera historia de amor, titulada Solo tú, con abundantes exteriores. En cierta escena la pareja llega a un pequeño hotel y entran al vestíbulo. Los seguimos con la cámara y descubrimos que las ventanas del vestíbulo prácticamente se habían borrado. La luz del día entraba a raudales.

Normalmente hubiésemos debido tapar esas ventanas y utilizar luz artificial desde afuera para tratar de armonizarla con la luz que traían los actores, pero para mí, en esa escena, los rostros eran más importantes que una correcta iluminación, para desesperación de mi segundo americano.

Es muy importante no cerrarse nunca, no empeñarse en que todo ha de ser de una determinada manera, no empantanarse en la rutina. Son muchos los que lo hacen. La rutina suele pesar más que las ideas nuevas.

Yo tengo un principio básico: escuchar, cumplir fielmente las intenciones del director. Ahí radica una parte de mi fuerza como operador y mi capacidad para trabajar con directores tan diferentes por todo el mundo. El conocimiento del oficio no basta. Un buen iluminador debe reunir otras cualidades como flexibilidad, diplomacia y sensibilidad. Cada día de rodaje es un juego de sentimientos, e importa mucho poder dejar a un lado irritaciones y conflictos.

Cada película es única y representa un nuevo desafío. Claro que uno se encuentra más seguro con un director, un equipo y actores que conocer, pero lo que hace la vida apasionante son precisamente las nuevas caras y las nuevas ideas. En cada película se aprende algo nuevo y yo quiero morir curioso.

Mientras siga sintiendo alegría en mi trabajo continuaré, y el día en que esa alegría se acabe, y llegue la última gran soledad, me lo tomaré con calma. Tengo la luz que me hace compañía. Y luz hay siempre.

(Fragmento del libro Culto a la luz.) 